\title{
IV. Zoologie.
}

\section{Blutegel aus Australien.}

In Australien kommen nach Schmarda zwci verschiedene Blutegel vor: Hirudo quinquestriata und II irudo tristriata. Dieselben werden seit einiger Zeit in London importirt, aber im Ganzen mit geringem Erfolg, theils, weil überhaupt der Bedarf abnimmt, anderentheils, weil diese Blutegel nicht das Ansehen der bei uns üblichen haben. (Pharm. Journ. London, July 1869.).

$H$.

\section{Ueber indische und chinesische Ichthyocolla,}

nach Aufzeichnungen ron $L$ éon Soubeiran, Clcland und Royle.

Die indische Ichthyocolla, die seit undenklichen Zeiten in ihrer Heimath in beträchtlichen Mengen verbraucht wird, hat erst gegen das Jahr 1839 bei den in Indien ansässigen Europäern Anwendung gefunden. Jetzt wird sie auch auf den Londoner Markt gebracht und findet raschen Absatz an Bierbrauer, die sie zum Klären des Bieres verwenden. Diese Ichthyocolla besteht aus den Schwimmblasen mehrer Fische des Ganges und der tropischen Meere, so des Polynemus tetradactylus, P. quadrifilis, P. Bola und Silurus raita.

Die indische I chth yocolla gelangt in zweierlei Formen in den Handel 1) in ovalen, 9" langen, 5 " breiten und $1 / 2 "$ dicken Stïcken; diese sind undurchsichtig, an der Aussenseite bräunlich, an der Innenfläche schneeweiss, oft perlmutterglänzend, besonders wenn man die dünnen Hïutchen entfernt. Sie besitzen einen schwachen Fischgeruch und haben das Aussehen, als wären sie unmittelbar nach dem Hernusnehmen aus den Fischen an der Sonne getrocknet worden.

2) In Exemplaren, die eine Länge von 6 bis $24 "$, eine Breite von $3-4^{\prime \prime}$ und eine Dicke von $1 / 10$ bis $1 / 6$ " erreichen; ihre Aussenseite erscheint weisslich, was von sunhängendem $\mathrm{K}$ alk herrührt, mit dem die Blasen bestreut worden sind. 